\title{
Diabetic Neuropathy in Spontaneously Diabetic Torii Rat
}

\author{
Tomohiko Sasase ${ }^{*}$ and Takeshi Ohta
}

\begin{abstract}
Japan Tobacco Inc., Central Pharmaceutical Research Institute, Biological/Pharmacological Research Laboratories, 1-1, Murasaki-cho, Takatsuki, Osaka 569-1125, Japan
\end{abstract}

\begin{abstract}
To aid in the study of diabetes and its complications, many diabetic animal models have been reported. Although most diabetic patients suffer type 2 diabetes, studies using type 2 diabetic animal models have been carried out less frequently. Spontaneously Diabetic Torii (SDT) rat, a non-obese type 2 diabetes model, shows neuropathies and severe ocular complications. Decreased nerve conduction velocity and thermal hypoalgesia were improved by insulin treatment, indicating that the peripheral neuropathies in SDT rats are caused by sustained hyperglycemia. Autonomic nerve dysfunctions such as decreased coefficients of variance of $R-R$ intervals $\left(C V_{R-R}\right)$ in electrocardiogram, functional gastrointestinal disorders, and voiding dysfunction are also observed in SDT rats. Therefore, SDT rat is a useful diabetic animal model for studies of diabetic neuropathies in type 2 diabetes and development of new drugs and therapies for diabetic neuropathies.
\end{abstract}

Keywords: SDT rat, diabetic neuropathy, nerve conduction velocity, coefficients of valiance of R-R intervals $\left(C V_{R-R}\right)$, insulin.

\section{INTRODUCTION}

Diabetes mellitus (DM) is one of the most common diseases, and more than half of all DM patients have diabetic complications such as diabetic retinopathy, diabetic nephropathy, or diabetic neuropathy. Among these complications, diabetic neuropathy is the most frequent and up to $50 \%$ of diabetics suffer some form of nerve damage [1]. Moreover, diabetic neuropathy causes foot ulceration and may lead to amputation, and may also lead to chronic pain with reduced quality of life. Most common among the diabetic neuropathies are diabetic peripheral neuropathy (DPN) and the diabetic autonomic neuropathy (DAN). Large clinical trials have indicated that strict control of blood glucose level in both type 1 and type 2 diabetes patients can delay the onset and progression of these diabetic neuropathies $[2,3]$.

To study DM and its complications, many diabetic animal models have been reportedly tested [4-8]. These animal models showing hyperglycemia were followed by complications in several tissues, including kidneys, nerves, and eyes. Spontaneously Diabetic Torii (SDT) rat is a new model for non-obese type 2 diabetes [9,10]. Although most DM patients suffer type 2 diabetes, studies using type 2 diabetic animal models have been carried out less frequently $[11,12]$. Therefore basic research using type 2 diabetic animal models is necessary for the development of new drugs and treatments for diabetic neuropathy. SDT rat shows marked hyperglycemia (Fig. 1A) and subsequent severe ocular complications [9, 10, 13-15] and nephropathy [16]. On the other hand, although SDT rats show all three major diabetic complications, only a few reports on neuropathies have been published [17-20]. Therefore in this article,

*Address correspondence to this author at the Japan Tobacco Inc., Central Pharmaceutical Research Institute, Biological/Pharmacological Research Laboratories, 1-1 Murasaki-cho, Takatsuki, Osaka 569-1125, Japan; Tel: +81 72681 9700; Fax: +81 72681 9722; E-mail: tomohiko.sasase@jt.com characteristics of diabetic neuropathies in SDT rats are overviewed.

\section{DIABETIC PERIPHERAL NEUROPATHY}

Peripheral nerve fibers are classified as large or small fibers. Motor nerve conduction velocity (MNCV) and sensory nerve conduction velocity (SNCV) defects in diabetic animals are markers of large myelinated fiber dysfunction [21, 22]. Wada et al. first reported the MNCV in SDT rats $[19,20]$. In their report, SDT rats showed decreased $\mathrm{MNCV}$ around 30 weeks of age. MNCV was decreased to $82 \%$ that of normal rats at 40 weeks of age and to $76 \%$ at 48 weeks of age (Fig. 1B). When the blood glucose levels were strictly controlled by insulin for 24 weeks, disorder in tail MNCV was significantly prevented (Fig. 2A, B). Therefore, it is clear that the decreased MNCV was caused by sustained hyperglycemia [18].

Small fibers (e.g. A $\delta$ and C-fiber) mediate sensation of temperature and pain as well as autonomic functions. Both hyper- and hypoalgesia are found in diabetic state. Duration of hyperglycemia, the severity of diabetic state, sex or species may affect progression to diabetic hyper- or hypoalgesia. While thermal hypoalgesia is reported in diabetic animals using tail-flick test or hot plate test [23-25], others have found hyperalgesia [26-28]. At 32 weeks of age, marked thermal hypoalgesia was observed in SDT rats by tail-flick test [17].

\section{DIABETIC AUTONOMIC NEUROPATHY}

Autonomic nerve functions are also impaired in diabetes. Coefficient of variance of $R-R$ intervals $\left(C_{R-R}\right)$ in electrocardiogram, a marker of autonomic nerve function, was significantly lower in diabetic SDT rats (44 weeks of age) compared to age-matched normal Sprague-Dawley (SD) rats (SDT rats have the SD rats as their background), indicating disorder of autonomic nerve function [17]. Twenty-four week administration of insulin prevented worsening of $\mathrm{CV}_{\mathrm{R}-\mathrm{R}}$ in SDT rats (Fig. 2C) [18]. The 


\section{A}

B
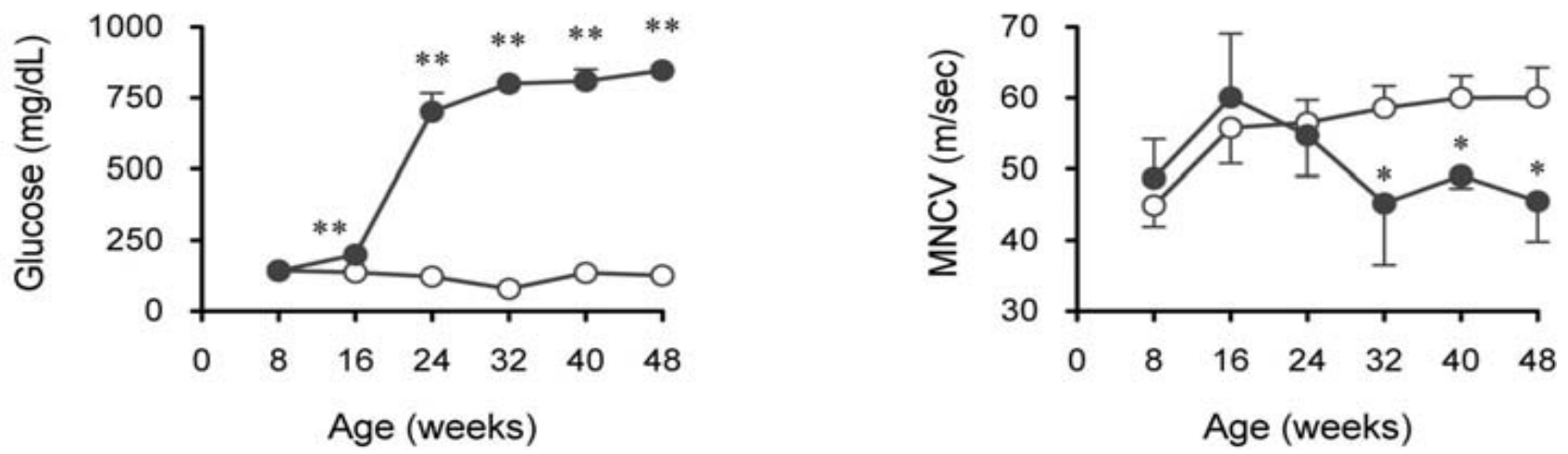

Fig. (1). Serial changes of (A) blood glucose level and (B) tibial motor nerve conduction velocity (MNCV) in SD rats (open circles) and SDT rats (closed circles). Figure B was kindly provided by Dr. Wada (Hirosaki University School of Medicine). Data represent means \pm S.E.M. $(\mathrm{n}=4.6){ }^{*} \mathrm{p}<0.05, * * \mathrm{p}<0.01$ ( $v s$ age-matched SD rat, unpaired $t$-test for (A), Mann-Whitney U-test for (B)).
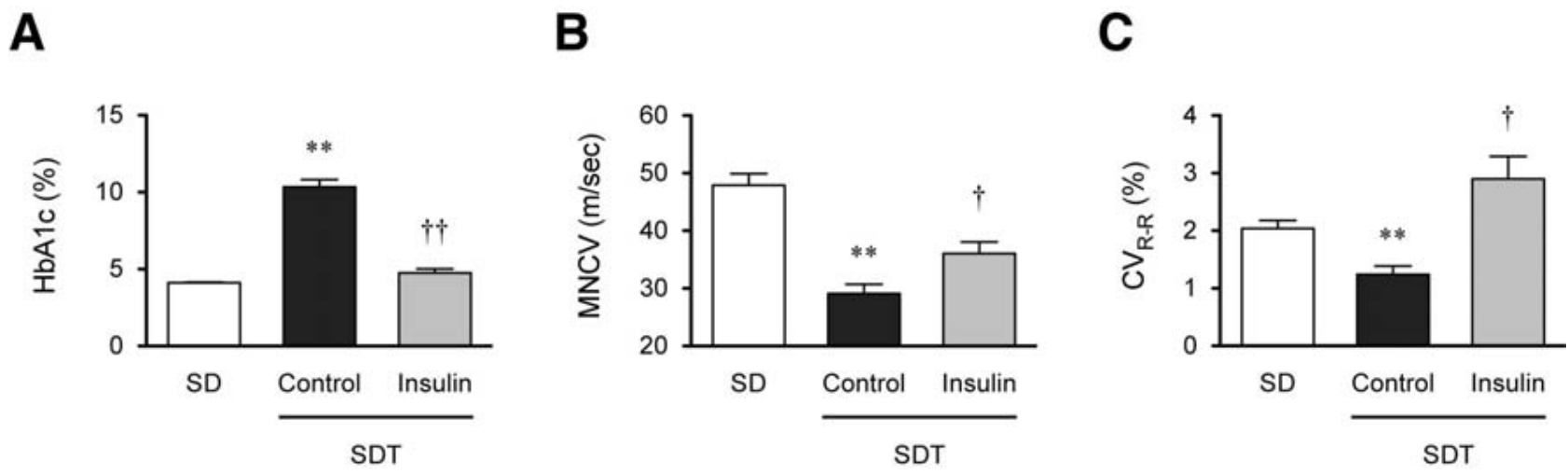

Fig. (2). Effect of blood glucose control by insulin on (A) HbA1c, (B) tail motor nerve conduction velocity (MNCV) and (C) coefficients of variance of $\mathrm{R}-\mathrm{R}$ intervals $\left(\mathrm{CV}_{\mathrm{R}-\mathrm{R}}\right)$ in electrocardiogram. Twenty four-weeks old SDT rats were treated with insulin pellets for 20 weeks. Data represent means \pm S.E.M. $(\mathrm{n}=3-6)$. ${ }^{* *} \mathrm{p}<0.01$ ( $v s$ age-matched SD rat, unpaired $t$-test), $\dagger \mathrm{p}<0.05, \dagger \dagger \mathrm{p}<0.01$ ( $v s$ control SDT rat, unpaired $t$ test).

impaired autonomic nerve is deeply associated with diabetic gastroenteropathy. Functional gastrointestinal disorders such as rapid gastrointestinal transit and diarrhea are observed in SDT rats [29]. As several reports on DAN have shown [30, 31], insulin therapy is effective on these diabetic gastrointestinal abnormalities in SDT rats [29]. Voiding dysfunction is also observed as a result of DAN. Bladder dysfunctions such as diabetic cystopathy are common symptoms among diabetic patients [32] and diabetic animal models [33] with DAN. Reduced production of nerve growth factor (NGF) in the bladder and dorsal root ganglia (DRG) was associated with voiding dysfunction attributable to defects in $\mathrm{A} \delta$ and $\mathrm{C}$-fiber bladder afferents in streptozotocin (STZ)-induced diabetic rats [34]. In SDT rats, increase in voided volume and inter-micturition interval related to the afferent limb neuropathy and the increase in voiding pressure related to urethral dysfunction were observed as diabetic bladder dysfunction [35].

\section{HISTOPATHOLOGY}

The histopathological characteristics of sural nerve in SDT rats are described by Wada et al. [19, 20]. Although neurologic deficits were not observed in sural nerve, incidence of degenerating nerve was increased in SDT rats. Morphologically, SDT rats revealed significant atrophy in myelinated nerve at 48 weeks of age: cross-sectional area was $88 \%$ that of normal rats. At this age, the number of small fibers was relatively increased in SDT rats. The number of endoneural blood vessels in SDT rats was comparable with that in normal rats; however, occluded vessels were found in SDT rats (Fig. 3). Considering that the main pathological findings in human diabetic nerves consist of progressive fiber loss and endoneural microangiopathy [5], SDT rat is a useful animal model of type 2 diabetes.

\section{TREATMENT OF DIABETIC NEUROPATHY}

Multiple mechanisms have been implicated in diabetic complications including diabetic neuropathies: increased polyol pathway, hexosamine pathway, and advanced glycation endproducts (AGEs) are well-known factors. Activation of protein kinase $\mathrm{C}$ beta $(\mathrm{PKC} \beta)$, through the de novo synthesis of diacylglycerol (DAG) is also observed under diabetic conditions. Although hyperglycemia is a 


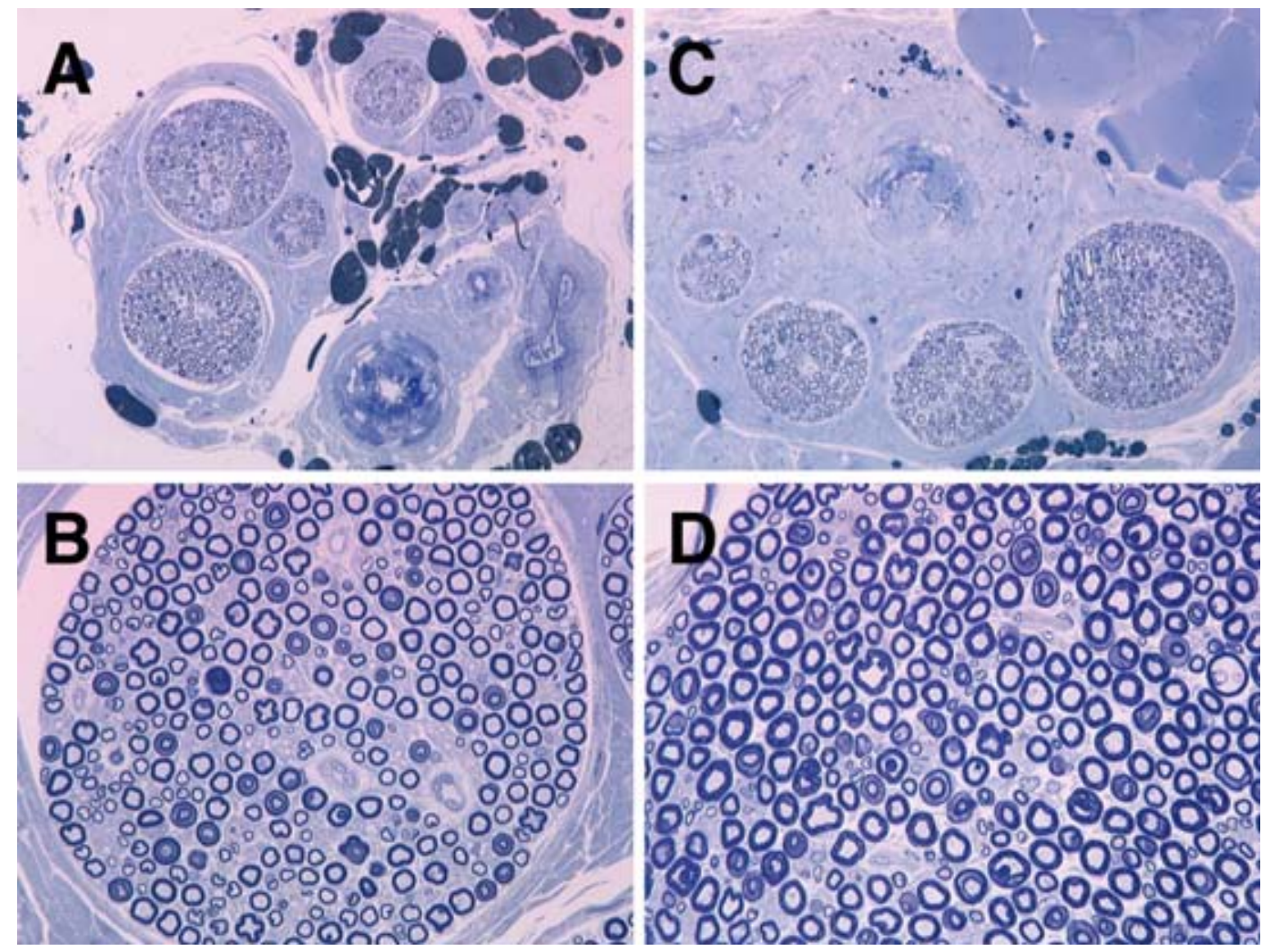

Fig. (3). Structural changes of the peripheral nerves. (A) Low and (B) high magnification of sural nerve from 12 months old SD rat. (C) Low and (D) high magnification of sural nerve from 12 months old SDT rat. Toluidine blue stain. Microphotographs were kindly provided by Dr. Wada.

major determinant of diabetic complications, current oral anti-hyperglycemic drugs have not shown sufficient efficacy to prevent the development of diabetic microvascular complications. Therefore, novel drugs for diabetic complications independent from hypoglycemic effect are desperately needed. Aldose reductase inhibitor (ARI) and PKC $\beta$ inhibitor were proven to prevent diabetic retinopathy without controlling blood glucose levels in SDT rats [17, 36]. Long-term treatment of a PKC $\beta$ selective inhibitor, JTT-
010, prevented diabetic neuropathy in SDT rats [17]. Twelve-week administration of JTT-010 prevented delay of $\mathrm{MNCV}$, and decreased $\mathrm{CV}_{\mathrm{R}-\mathrm{R}}$ and thermal hypoalgesia in SDT rats without affecting blood glucose levels. However, JTT-010 did not prevent hyperglycemia-induced retinal abnormalities in SDT rats (e.g. abnormal retinal vascular formation, protruded optic disc). Therefore, it seems that the different factor(s) contribute to progression of diabetic neuropathy and diabetic retinopathy in SDT rats.
A

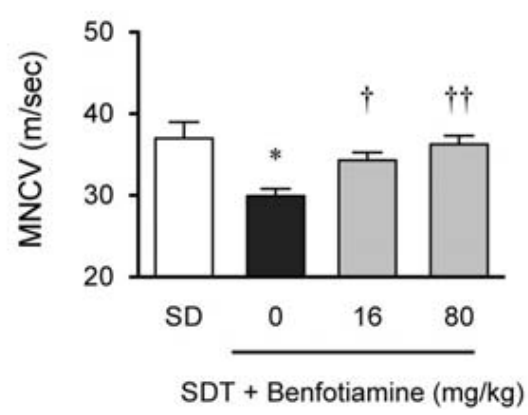

B

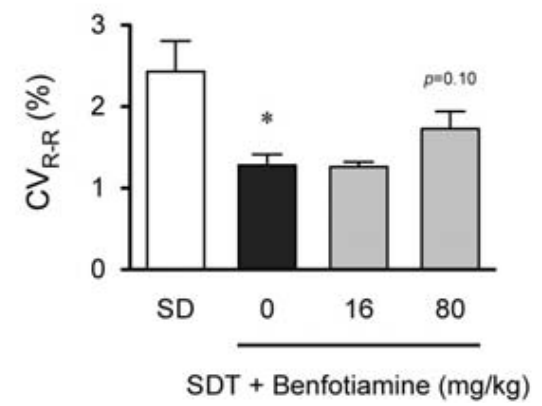

C

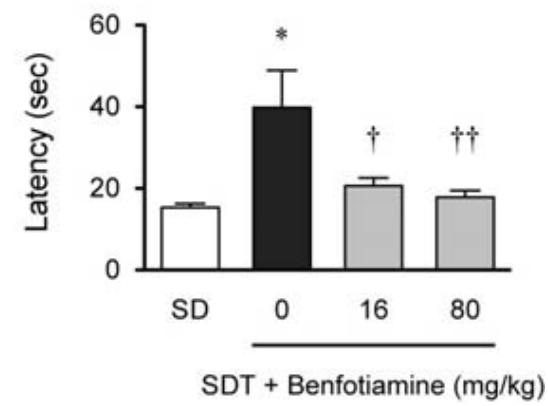

Fig. (4). Effect of benfotiamine on (A) tail MNCV, (B) $\mathrm{CV}_{\mathrm{R}-\mathrm{R}}$, and (C) thermal hypoalgesia (tail-flick test). Twenty-weeks old SDT rats were treated with benfotiamine by food admixture for 12 weeks. Data represent means \pm S.E.M. ( $\mathrm{n}=7-8) .{ }^{*} \mathrm{p}<0.05$ ( $v s$ SD rat, unpaired $t$-test), $\dagger \mathrm{p}<0.05, \dagger \dagger \mathrm{p}<0.01$ ( $v$ s untreated SDT rat, Dunnett's test). 
Benfotiamine reduces all four major pathways (polyol pathway, hexosamine pathway, AGE pathway, and DAGPKC pathway) by activating transketolase, a thiaminedependent pentose phosphate pathway enzyme. This liposoluble prodrug of thiamine exhibits effects on peripheral nerve function as well as on diabetic retinopathy $[37,38]$. Benfotiamine clearly showed blood glucoseindependent effect on DPN/DAN in SDT rats, as well as blood glucose control by insulin, indicating that the SDT rat is a helpful model for research and development of new pharmaceuticals. Twelve-week treatment of benfotiamine (20-32 weeks of age) improved MNCV with dose dependency. Administration of benfotiamine also tended to ameliorate $C_{R-R}$ and prevented elevation of tail-flick threshold significantly (Fig. 4). Biochemical parameters and body weight of SDT rats were not affected by benfotiamine.

\section{CONCLUSION}

In conclusion, neuropathies in SDT rats are caused by sustained hyperglycemia and therefore SDT rat is useful diabetic animal model for studies in diabetic neuropathies in type 2 diabetes and for the development of new drugs and therapies for diabetic neuropathies.

\section{ACKNOWLEDGEMENTS}

The author is grateful to Dr. Ryuichi Wada and Prof. Soroku Yagihashi (Hirosaki University School of Medicine) for their meaningful contributions regarding diabetic neuropathies in SDT rat and their kindness providing valuable data and microphotographs.

\section{REFERENCES}

[1] Boulton AJ, Malik RA, Arezzo JC. Sosenko JM. Diabetic somatic neuropathies. Diabetes Care 2004; 27: 1458-86.

[2] The Diabetes Control and Complications Trial Research Group. The effect of intensive treatment of diabetes on the development and progression of long-term complications in insulin-dependent diabetes mellitus. N Engl J Med 1993; 329: 977-86.

[3] UK Prospective Diabetes Study (UKPDS) Group. Intensive bloodglucose control with sulphonylureas or insulin compared with conventional treatment and risk of complications in patients with type 2 diabetes (UKPDS 33). Lancet 1998; 352: 837-53.

[4] Britland S, Sharma A. A new perspective on myelinated nerve fibre pathology in experimental diabetes. Diabetes Res 1990; 15: 69-75.

[5] Yagihashi S. Pathology and pathogenetic mechanisms of diabetic neuropathy. Diabetes Metab Rev 1995; 11: 193-225.

[6] Yagihashi S, Sima AA. Diabetic autonomic neuropathy. The distribution of structural changes in sympathetic nerves of the BB rat. Am J Pathol 1985; 121: 138-47.

[7] Yagihashi S, Sima AA. Diabetic autonomic neuropathy in the BB rat. Ultrastructural and morphometric changes in sympathetic nerves. Diabetes 1985; 34: 558-64.

[8] Yagihashi S, Wada R, Kamijo M, Nagai K.. Peripheral neuropathy in the WBN/Kob rat with chronic pancreatitis and spontaneous diabetes. Lab Invest 1993; 68: 296-307.

[9] Shinohara M, Masuyama T, Shoda T, et al. A new spontaneously diabetic non-obese Torii rat strain with severe ocular complications. Int J Exp Diabetes Res 2000; 1: 89-100.

[10] Shinohara M, Masuyama T, Kakehashi A. The Spontaneously Diabetic Torii (SDT) rat with retinopathy lesions resembling those of humans. In: Shafrir E, Eds. Animal models of diabetes: frontiers in research. 2nd ed. Boca Raton (FL): CRC Press 2007; pp. 311-21.

[11] Li F, Abatan OI, Kim H, et al. Taurine reverses neurological and neurovascular deficits in Zucker diabetic fatty rats. Neurobiol Dis 2006; 22: 669-76.

[12] Oltman CL, Coppey LJ, Gellett JS, et al. Progression of vascular and neural dysfunction in sciatic nerves of Zucker diabetic fatty and Zucker rats. Am J Physiol Endocrinol Metab 2005; 289: E11322.
[13] Kakehashi A, Saito Y, Mori K, et al. Characteristics of diabetic retinopathy in SDT rats. Diabetes Metab Res Rev 2006; 22: 45561.

[14] Sasase T. Pathophysiological characteristics of diabetic ocular complications in Spontaneously Diabetic Torii (SDT) rat. J Ophthalmol 2010; 2010: 615-41.

[15] Sasase T, Ohta T, Ogawa N, et al. Preventive effects of glycaemic control on ocular complications of Spontaneously Diabetic Torii rat. Diabetes Obes Metab 2006; 8: 501-7.

[16] Ohta T, Matsui K, Miyajima K, et al. Effect of insulin therapy on renal changes in spontaneously diabetic Torii rats. Exp Anim 2007; 56: $355-62$.

[17] Sasase T, Morinaga H, Abe T, et al. Protein kinase C beta inhibitor prevents diabetic peripheral neuropathy, but not histopathological abnormalities of retina in Spontaneously Diabetic Torii rat. Diabetes Obes Metab 2009; 11: 1084-7.

[18] Sasase T, Ohta T, Ogawa N, et al. Diabetic complications of Spontaneously Diabetic Torii rat. Diabetes 2005; 54 (Suppl 1): A221.

[19] Wada R, Yajima N, Shinohara M, Yagihashi S. Peripheral neuropathy in a newly-established strain of non-obese spontaneously-onset type 2 diabetic Torii (SDT) rat. In: Diabetic Complications: Progress through Animal Models; 2003 Oct 20-21; Bethesda, USA.

[20] Wada R, Yajima N, Shinohara M, Yagihashi S. Peripheral neuropathy in new non-obese type 2 diabetic model, Spontaneously Diabetic Torii (SDT) rats (in Japanese). Diabetes Frontier 2004; 15: 731.

[21] Greene DA, De Jesus PV, Jr., Winegrad AI. Effects of insulin and dietary myoinositol on impaired peripheral motor nerve conduction velocity in acute streptozotocin diabetes. J Clin Invest 1975; 55: 1326-36.

[22] Malone JI, Lowitt S, Korthals JK, Salem A, Miranda C. The effect of hyperglycemia on nerve conduction and structure is age dependent. Diabetes 1996; 45: 209-15

[23] Akunne HC, Soliman KF. The role of opioid receptors in diabetes and hyperglycemia-induced changes in pain threshold in the rat. Psychopharmacology (Berl) 1987; 93: 167-72.

[24] Apfel SC, Arezzo JC, Brownlee M, Federoff H, Kessler JA. Nerve growth factor administration protects against experimental diabetic sensory neuropathy. Brain Res 1994; 634: 7-12.

[25] Kolta MG, Ngong JM, Rutledge LP, Pierzchala K, Van Loon GR. Endogenous opioid peptide mediation of hypoalgesic response in long-term diabetic rats. Neuropeptides 1996; 30: 335-44.

[26] Forman LJ, Estilow S, Lewis M, Vasilenko P. Streptozocin diabetes alters immunoreactive beta-endorphin levels and pain perception after $8 \mathrm{wk}$ in female rats. Diabetes 1986; 35: 1309-13.

[27] Ohsawa M, Kamei J. Possible involvement of spinal protein kinase $\mathrm{C}$ in thermal allodynia and hyperalgesia in diabetic mice. Eur $\mathrm{J}$ Pharmacol 1999; 372: 221-8.

[28] Simon GS, Dewey WL. Narcotics and diabetes. I. The effects of streptozotocin-induced diabetes on the antinociceptive potency of morphine. J Pharmacol Exp Ther 1981; 218: 318-23.

[29] Yamada K, Hosokawa M, Fujimoto S, et al. The spontaneously diabetic Torii rat with gastroenteropathy. Diabetes Res Clin Pract 2007; 75: 127-34.

[30] Nowak TV, Harrington B, Kalbfleisch JH, Amatruda JM. Evidence for abnormal cholinergic neuromuscular transmission in diabetic rat small intestine. Gastroenterology 1986; 91: 124-32.

[31] Yoshida T, Nishioka H, Yoshioka K, et al. Effect of aldose reductase inhibitor ONO 2235 on reduced sympathetic nervous system activity and peripheral nerve disorders in STZ-induced diabetic rats. Diabetes 1987; 36: 6-13.

[32] Frimodt-Moller C. Diabetic cystopathy: epidemiology and related disorders. Ann Intern Med 1980; 92: 318-21.

[33] Malmgren A, Andersson PO, Uvelius B. Bladder function in rats with short- and long-term diabetes; effects of age and muscarinic blockade. J Urol 1989; 142: 1608-14.

[34] Sasaki K, Chancellor MB, Phelan MW, et al. Diabetic cystopathy correlates with a long-term decrease in nerve growth factor levels in the bladder and lumbosacral dorsal root Ganglia. J Urol 2002; 168: 1259-64.

[35] Matsumoto Y, Torimoto K, Matsuyoshi H, et al. Long-term effects of diabetes mellitus on voiding function in a new model of type 2 diabetes mellitus, the Spontaneously Diabetic Torii (SDT) rat. Biomed Res 2009; 30: 331-5. 
[36] Kakehashi A, Saito Y, Ono R, et al. Prevention of Diabetic Ocular Complications in Spontaneously Diabetic Torii Rats by Aldose Reductase Inhibitor Fidarestat. Invest Ophthalmol Vis Sci 2004; 45 (Suppl): 3248.

[37] Hammes HP, Du X, Edelstein D, et al. Benfotiamine blocks three major pathways of hyperglycemic damage and prevents experimental diabetic retinopathy. Nat Med 2003; 9: 294-9.
[38] Stracke H, Hammes HP, Werkmann D, et al. Efficacy of benfotiamine versus thiamine on function and glycation products of peripheral nerves in diabetic rats. Exp Clin Endocrinol Diabetes 2001; 109: 330-6.

Received: April 27, 2010

Revised: December 11, 2010

Accepted: January 15, 2011

(C) Sasase and Ohta; Licensee Bentham Open.

This is an open access article licensed under the terms of the Creative Commons Attribution Non-Commercial License (http://creativecommons.org/licenses/by-nc/3.0/) which permits unrestricted, non-commercial use, distribution and reproduction in any medium, provided the work is properly cited. 